\title{
Canadian economic impact of improved workplace productivity in patients with major depressive disorder treated with vortioxetine
}

\author{
Jean Lachaine, ${ }^{1,2 *}$ Catherine Beauchemin, ${ }^{2}$ Joëlle Bibeau, ${ }^{2}$ Julie Patenaude, ${ }^{2}$ (I) \\ Pratap Chokka, ${ }^{3}$ (D) Jean Proulx, ${ }^{4}$ and Joanna Bougie ${ }^{4}$
}

\footnotetext{
${ }^{1}$ Faculté de pharmacie, Université de Montréal, Montreal, Quebec, Canada

${ }^{2}$ PeriPharm Inc., Montreal, Quebec, Canada

${ }^{3}$ Grey Nuns Community Hospital, Edmonton, Alberta, Canada

${ }^{4}$ Lundbeck Canada Inc., Montreal, Quebec, Canada
}

Objective. The AtWoRC study is an interventional, open-label Canadian study that demonstrated significant improvements in cognitive function and workplace productivity in patients with major depressive disorder (MDD) treated with vortioxetine for a current major depressive episode. The objective of the present analysis was to assess the Canadian economic impact of improved workplace productivity based on the AtWoRC study results.

Methods. The economic impact of improved productivity in patients with MDD treated with vortioxetine was assessed over a 52-week period considering productivity loss due to absenteeism and presenteeism using the standard human capital approach and an employer's perspective. Absenteeism was measured with the Work Productivity and Activity Impairment questionnaire; and presenteeism with the Work Limitation Questionnaire. Productivity gains following treatment initiation with vortioxetine were estimated using the difference from baseline.

Results. In the AtWoRC study, patients at baseline reportedly missed, in the past 7 days, an average of $8.1 \mathrm{~h}$ due to absenteeism and $3.0 \mathrm{~h}$ due to presenteeism. Following 52 weeks of treatment with vortioxetine, patients reportedly missed an average of $4.9 \mathrm{~h}$ due to absenteeism and $2.0 \mathrm{~h}$ due to presenteeism. This improved workplace productivity translated into savings of C\$110.64 for 1 week of work following 52 weeks of treatment. The cumulative 52-week economic impact showed potential savings of $\mathrm{C} \$ 4,550$ when factoring in the cost of therapy.

Conclusion. This study suggested that workplace productivity gain due to an improvement in symptoms of MDD following treatment with vortioxetine will lead to substantial cost savings for the Canadian economy.

Received 2 August 2018; Accepted 1 March 2019; First published online 23 May 2019

Key words Major depressive disorder, cognitive dysfunction, workplace productivity, economic impact, human capital method, Work Limitation Questionnaire, vortioxetine, Work Productivity and Activity Impairment.

Mental disorders are associated with significant functional impairment that can have a detrimental effect on one's ability to perform various daily activities, including social, family, and workplace functioning. Major depressive disorder (MDD) stands among the most prevalent

*Address correspondence to: Jean Lachaine, PeriPharm, Inc., 600-5858 chemin de la Côte-des-Neiges, Montreal, Quebec H3S 1Z1, Canada. (Email: jean.lachaine@peripharm.com)

All authors were involved at all stages of manuscript development, approved the final version of the manuscript to be published, and agreed to act as guarantors of the work. We would also like to thank Kimberly Guinan for her contribution to the data analysis. mental disorders and has been associated with important economic burden, mainly attributable to indirect costs of productivity loss. ${ }^{1-4}$ In Canada, the lifetime and annual prevalence of MDD is estimated at $9.9 \%$ and $3.9 \%$, respectively. ${ }^{4,5}$ A Canadian community health survey conducted in 2003 estimated the total economic burden associated with mental illness, which includes MDD, at C $\$ 51$ billion. ${ }^{6}$ More specifically, the Canadian economic impact for MDD has been estimated at C $\$ 32.3$ billion a year in $2016 .^{7}$

MDD is a complex and heterogeneous disorder associated with symptoms such as persistent feeling of 
sadness, impaired cognitive function, sleep disturbance, and general loss of pleasure/interest. ${ }^{8}$ Cognitive symptoms are one of the most predominant symptoms associated with poor patient outcomes, work and functional impairment, and increased clinical and economic burden. ${ }^{9}$ Current treatments for MDD help resolve mood symptoms in many patients, but leave more than $30 \%$ of them with residual symptomatology, among which cognitive symptoms figure prominently. ${ }^{10,11}$ Considering the importance of cognitive symptoms and their impact on daily functioning and work productivity, even after remission of mood symptoms, the Diagnostic and Statistical Manual of Mental Disorders, 5th Edition, gives evidence-based guidelines for treating cognitive dysfunction associated with MDD. ${ }^{12}$

In pivotal clinical trials, vortioxetine has demonstrated significant clinical efficacy on mood symptoms of depression. ${ }^{13} \mathrm{~A}$ recent meta-analysis by Cipriani et al. comparing 21 antidepressants in over 116,000 patients also highlighted that vortioxetine was superior to placebo in improving mood symptoms, as assessed by the MADRS and HAM-D scales, while also demonstrating a strong acceptability profile. ${ }^{14}$ In addition, improvement on subjective as well as objective neuropsychological measures of cognitive function, compared to placebo, has also been reported in adult patients with MDD. ${ }^{15-20}$ In fact, the 2016 Canadian guidelines for the management of adults with MDD recommend vortioxetine as first-line treatment for MDD, including for patients with cognitive symptoms. $^{21}$

The Assessment in Work productivity and the

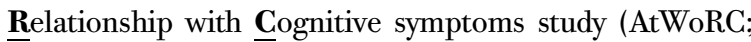
NCT02332954) is an interventional, open-label, Canadian study primarily designed to assess the association between cognitive symptoms and work productivity in gainfully employed patients with MDD and who were being treated with $10-20 \mathrm{mg}$ of vortioxetine daily. ${ }^{22,23}$ The AtWoRC study was conducted in 26 centers across Canada by 9 psychiatrists and 17 primary care physicians. To be eligible, patients had to be currently experiencing a confirmed major depressive episode (MDE) for at least 3 months, and to be employed full-time (described as $\geq 20 \mathrm{~h}$ weekly) or enrolled in full-time post-secondary studies or vocational training. The AtWoRC study also aimed to describe the change from baseline in functioning and work productivity for patients receiving vortioxetine for an MDE over a 52-week period, using several instruments such as the Work Limitations Questionnaire (WLQ), the Sheehan Disability Scale (SDS), the Work Productivity and Activity Impairment (WPAI) questionnaire, and the World Health Organization Disability Assessment 2.0 (WHODAS 2.0) questionnaire. Patients included in the study initiated vortioxetine treatment after the baseline visit, and productivity outcomes were measured at baseline and at 4, 8, 12, 26, 39, and
52 weeks using these questionnaires. Results at both 12- and 52-week time points demonstrated significant and clinically relevant improvements for mood, cognitive, productivity, and functional outcomes, with continued improvement observed throughout the study. ${ }^{22,23}$

The objective of the present analysis was to assess the economic impact, from an employer's perspective, of improved productivity in patients with MDD treated with vortioxetine over 52 weeks, based on the AtWoRC study results.

\section{Materials and Methods}

\section{Data source}

Data on patient productivity improvement from baseline over a 52-week period were retrieved from the AtWoRC study. ${ }^{22,23}$ Workplace productivity measurement included both missed work-days due to illness (absenteeism) and periods of less productive work during paid work-hours (presenteeism). Absenteeism was measured using the WPAI questionnaire, while presenteeism was measured using the WLQ.

The WPAI is a validated questionnaire composed of six questions that can be translated into four scores expressing the level of impairment in the last 7 days, with higher numbers reflecting greater impairment and decreased productivity. ${ }^{24}$ The four scores obtained were: absenteeism (work time missed), presenteeism (impairment at work/reduced on-the-job effectiveness), work productivity loss (overall work impairment/absenteeism plus presenteeism), and activity impairment. The questionnaire scores present the work time missed because of health problems and the degree to which work or regular activities were limited due to health problems, both of which can be converted into monetary value. ${ }^{25}$ For this analysis, only the results of the second question of the WPAI questionnaire, measuring the number of workhours lost in the past 7 days, were used. Although the WPAI questionnaire also assesses presenteeism, its estimate is based on a qualitative measure, through a single question, by asking how much the patient's productivity has been affected by MDD. ${ }^{25}$

The estimate of presenteeism was based on a more accurate measure using the $\mathrm{WLQ}$, which is a 25 -item validated questionnaire that aims to measure the impact of chronic disease on workplace productivity and presents important evidence in mood disorders. ${ }^{25}$ The items are aggregated into four scales to measure the following aspects of productivity: time management, physical demands, mental-interpersonal demands, and output demands. Scale scores range from 0 to 100,0 being limited none of the time and 100 being limited all of the time. The WLQ scores represent the percentage decrement in work due to health problems in the previous 2 weeks. The weighted sum of scores from the 
four scales is then used to calculate the WLQ productivity loss score, which represents the productivity loss relative to healthy controls. ${ }^{25,26}$

\section{Data analysis}

\section{Productivity loss data}

Absenteeism and presenteeism data were used to estimate the global economic impact of improved productivity from baseline in patients with MDD and who were being treated with vortioxetine over a 52 -week period. In order to estimate the average weekly working hours of patients in the AtWoRC study at baseline and during the following 52 weeks, the average number of hours lost due to absenteeism per week was subtracted from the average number of hours worked per week by the Canadian general population. The average number of hours worked by the Canadian general population was estimated at $30.2 \mathrm{~h}$, according to Statistics Canada. ${ }^{27}$ Subsequently, in order to take into account presenteeism due to MDD at baseline and during the following 52 weeks, the mean number of unproductive hours per week while at work was estimated using the WLQ. Specifically, the number of unproductive hours while at work, as previously described, was subtracted from the remaining weekly working hours calculated by excluding the hours of absenteeism. This method allowed the capturing of productivity loss associated with presenteeism only for the hours present at work, thus avoiding double-counting by applying presenteeism to hours absent from work.

The improvement in workplace productivity from baseline to week 52, in terms of hours of productive work gained over the weeks, has to be transposed into monetary value to estimate the global economic impact of workplace productivity improvement.

\section{Productivity loss monetization}

The human capital method (HCM) was used to translate productivity loss data into monetary value. It takes the employer's perspective and counts any hour not worked as an hour lost. Specifically, the HCM calculates the productivity loss by multiplying the number of hours missed due to illness (absenteeism) or due to periods of less productive work during paid work-hours (presenteeism) by the mean hourly wage. ${ }^{28}$ The weekly economic impact of the improved productivity over 52 weeks of treatment with vortioxetine was estimated based on the average hourly wage of C\$26.68 in Canada, as per December 2017 Canadian statistics. ${ }^{29}$ In addition, the cumulative economic impact of improved productivity over 52 weeks was estimated by summing the weekly economic impact. For the weeks between the study visits, the mean variation of economic impact was added to the previous week's value assuming a constant variation between visits. For the purpose of this analysis, the cost of vortioxetine was also considered in the cumulative economic impact by using the maximum recommended dose of $20 \mathrm{mg}$ daily, which was estimated at C\$21.77 per week. ${ }^{30}$ Costs are presented in 2017 Canadian dollars (C\$).

Loss of follow-up in the AtWoRC study

At the end of 52 weeks of treatment in the AtWoRC study, approximately $45 \%$ of patients did not complete the study, with the main reason being withdrawal of consent that prevented further participation in the study. Patient attrition in AtWoRC was comparable to other long-term data on vortioxetine as shown in a pooled analysis of other 52-week studies. ${ }^{31}$ Consequently, the absenteeism and presenteeism values at each visit were estimated using two different approaches of imputing missing data.

The baseline observation carried forward (BOCF) approach was considered for the base case analysis. Using this approach, baseline values were attributed to all patients with missing data for the remaining weeks of the study period, therefore assuming that these patients would not benefit from improved work productivity.

In a complementary economic impact analysis, a modified BOCF (mBOCF) approach was considered. For this approach, missing data were attributed with the presenteeism and absenteeism values of the visit preceding the missing data for the first subsequent visit, while baseline values were attributed for all other subsequent visits until 52 weeks.

\section{Results}

The AtWoRC baseline characteristics of all patients treated $(n=219)$, of which 107 patients received vortioxetine as their first treatment and 112 switched to vortioxetine from another treatment, are presented in Table $1 .{ }^{23}$ Switched patients were significantly older than first treatment patients and had longer disease duration. ${ }^{23}$ For the AtWoRC study, the results were reported for the full analysis set (FAS) of 199 patients (valid baseline assessment of patients who took at least one dose of vortioxetine and who attended at least one post-baseline study visit). ${ }^{22,23}$ Patients were classified as having not been treated with another antidepressant for the current MDE (first treatment subgroup; $n=97$ ) or having inadequate response to a previous antidepressant for the current MDE (switch subgroup; $n=102$ ). ${ }^{22,23}$ Regarding the WPAI and WLQ questionnaires, the results were reported for a smaller number of patients. Accordingly, due to missing responses, the number of missed workhours was reported for 195 patients (total cohort), of which 94 patients were in the first treatment and 101 in the switched subgroup. Regarding the WLQ questionnaire, due to incomplete responses, the results were reported for 186 patients (total cohort), of which 
TABLE 1. Baseline patient demographics ${ }^{\mathrm{a}}$

\begin{tabular}{|c|c|c|c|}
\hline & First treatment $(n=107)$ & Switch $(n=112)$ & Total $(n=219)$ \\
\hline Mean age, years $(S D)^{*}$ & $38.9(12.7)$ & $42.6(12.0)$ & $40.8(12.5)$ \\
\hline Female, \% ( $n)$ & $70.1(75)$ & $68.8(77)$ & $69.4(152)$ \\
\hline Caucasian, \% ( $n)$ & $93.5(100)$ & $94.6(106)$ & $94.1(206)$ \\
\hline \multirow[t]{2}{*}{ Mean time since MDD diagnosis, years (SD)* } & $5.6(6.5)$ & $11.0(11.3)$ & $8.4(9.6)$ \\
\hline & First treatment $(n=97)$ & Switch $(n=102)$ & FAS $(n=199)$ \\
\hline \multicolumn{4}{|l|}{ Highest level of education, \% (n) } \\
\hline High school or less & $37.1(36)$ & $40.2(41)$ & $38.7(77)$ \\
\hline College & 40.2 (39) & $37.3(38)$ & $38.7(77)$ \\
\hline University & $14.4(14)$ & $11.8(12)$ & $13.1(26)$ \\
\hline Postgraduate & $1.0(1)$ & $7.8(8)$ & $4.5(9)$ \\
\hline \multicolumn{4}{|l|}{ Employment status, \% (n) } \\
\hline Employment/independent & $89.7(87)$ & $94.1(96)$ & $92.0(183)$ \\
\hline Full-time vocational & $4.1(4)$ & $1.0(1)$ & $2.5(5)$ \\
\hline Full-time postsecondary student & $6.2(6)$ & $2.9(3)$ & $4.5(9)$ \\
\hline \multicolumn{4}{|l|}{ Occupation, \% $(n)$} \\
\hline Manufacturing & $5.2(5)$ & $2.9(3)$ & $4.0(8)$ \\
\hline Professional & $8.2(8)$ & $7.8(8)$ & $8.0(16)$ \\
\hline Service staff & $9.3(9)$ & $13.7(14)$ & $11.6(23)$ \\
\hline Sales & $12.4(12)$ & $10.8(11)$ & $11.6(23)$ \\
\hline Clerical & $12.4(12)$ & $14.7(15)$ & $13.6(27)$ \\
\hline Healthcare & $9.3(9)$ & $7.8(8)$ & $8.5(17)$ \\
\hline Agriculture & $0(0)$ & $1.0(1)$ & $0.5(1)$ \\
\hline Construction & $6.2(6)$ & $3.9(4)$ & $5.0(10)$ \\
\hline Other & $27.8(27)$ & $30.4(31)$ & $29.1(58)$ \\
\hline
\end{tabular}

${ }^{a}$ For patient demographics, all patients treated were assessed. For employment status, patients in the full analysis set (FAS) were assessed. * Significantly different between first treatment and switched groups. Table adapted from Chokka et al. (2019). ${ }^{23}$

TABLE 2. Number of missed work-hours in the past 7 days (absenteeism), according to the BOCF approach

\begin{tabular}{lll} 
Cohort & Timescale & $\begin{array}{c}\text { Mean work-hours } \\
\text { missed }^{\mathrm{a}, \mathrm{b}}(\mathrm{SD})\end{array}$ \\
\hline Total $(n=195)$ & Baseline & $8.1(12.09)$ \\
& Week 52 & $4.9(10.56)$ \\
First treatment $(n=94)$ & Baseline & $7.4(12.07)$ \\
& Week 52 & $3.7(8.42)$ \\
Switch $(n=101)$ & Baseline & $8.7(12.14)$ \\
& Week 52 & $6.0(12.19)$ \\
\hline
\end{tabular}

aBased on the WPAI questionnaire and considering a recall period of 7 days.

${ }^{b}$ At week 52 , baseline values were attributed to all patients with missing data (total: $n=81$; first treatment: $n=35$; switch: $n=$ 46) for the remaining weeks of the study period. Mean work-hours missed was calculated with the formula:

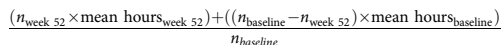

90 patients were in the first treatment and 96 in the switched subgroup.

\section{Work performance outcomes}

\section{Absenteeism}

As presented in Table 2, according to the scores of the WPAI questionnaire, patients at baseline reported an average work productivity loss due to absenteeism of $8.1(\mathrm{SD}=12.09), 7.4(\mathrm{SD}=12.07)$, and $8.7(\mathrm{SD}=$ 12.14) hours per week for the total cohort, "first treatment", and "switched" subgroups, respectively. Using the BOCF approach, the average absenteeism at week 52 was reduced to $4.9(\mathrm{SD}=10.56), 3.7(\mathrm{SD}=8.42)$, and $6.0(\mathrm{SD}=12.19)$ missed hours per week for the total cohort, "first treatment", and "switched" subgroups, respectively. When analyzing the unadjusted data, the change in WPAI score from baseline to week 52 was statistically significant $(p<0.001$ for total cohort, first treatment, and switched subgroups). ${ }^{23}$

\section{Presenteeism}

As presented in Table 3, the baseline results of WLQ scores showed an average workplace productivity loss of $13.4 \%(\mathrm{SD}=4.55), 13.2 \%(\mathrm{SD}=4.63)$, and $13.6 \%$ $(\mathrm{SD}=4.49)$, representing $2.96,3.01$, and $2.92 \mathrm{missed}$ hours due to presenteeism at baseline for the total cohort, "first treatment", and "switched" subgroups, respectively. Using the BOCF approach, productivity loss at work at 52 weeks of treatment reduced to $8.02 \%$ (SD = $4.55), 7.94 \%(\mathrm{SD}=4.97)$, and $8.13 \%(\mathrm{SD}=4.12)$, representing 2.03, 2.11, and 1.97 missed hours for the total cohort, "first treatment", and "switched" subgroup, respectively. When analyzing the unadjusted data, 
TABLE 3. WLQ productivity loss (\%) and number of unproductive work-hours in the past 7 days (presenteeism), according to the BOCF approach

\begin{tabular}{llrl} 
& \multicolumn{3}{c}{$\begin{array}{c}\text { Mean WLQ } \\
\text { productivity }\end{array}$} \\
Cohort & Timescale & \multicolumn{1}{c}{ loss (\%) (SD) } & Hours \\
\hline \multirow{2}{*}{ Total $(n=186)$} & Baseline & $13.4(4.55)$ & 2.96 \\
& Week 52 & $8.0(4.56)$ & 2.03 \\
First treatment $(n=90)$ & Baseline & $13.2(4.63)$ & 3.01 \\
& Week 52 & $7.9(4.97)$ & 2.11 \\
Switch $(n=96)$ & Baseline & $13.6(4.49)$ & 2.92 \\
& Week 52 & $8.1(4.11)$ & 1.97 \\
\hline
\end{tabular}

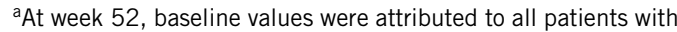
missing data (total: $n=76$; first treatment: $n=33$; switch: $n=$ 43) for the remaining weeks of the study period. Mean number of unproductive work-hours was calculated with the formula:

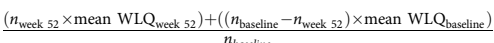

TABLE 4. Weekly economic impact associated with improve productivity following a 52-week treatment with vortioxetine according to the BOCF approach

\begin{tabular}{|c|c|c|c|c|}
\hline Cohort & $\begin{array}{l}\text { Time } \\
\text { scale }\end{array}$ & $\begin{array}{c}\text { Total } \\
\text { weekly } \\
\text { productive } \\
\text { work } \\
\text { (hours) }\end{array}$ & $\begin{array}{l}\text { Improved } \\
\text { productivity } \\
\text { from } \\
\text { baseline } \\
\text { (hours) }\end{array}$ & $\begin{array}{c}\text { Weekly } \\
\text { economic } \\
\text { impact from } \\
\text { improved } \\
\text { productivity }\end{array}$ \\
\hline Total & $\begin{array}{l}\text { Baseline } \\
\text { Week } 52\end{array}$ & $\begin{array}{l}19.14 \\
23.29\end{array}$ & $\begin{array}{c}- \\
4.15\end{array}$ & $c \stackrel{-}{C} \$ 110.64$ \\
\hline $\begin{array}{l}\text { First } \\
\text { treatment }\end{array}$ & $\begin{array}{r}\text { Baseline } \\
\text { Week } 52\end{array}$ & $\begin{array}{l}19.79 \\
24.40\end{array}$ & $\begin{array}{c}- \\
5.26\end{array}$ & $\begin{array}{c}- \\
\mathrm{C} \$ 140.32\end{array}$ \\
\hline Switch & $\begin{array}{l}\text { Baseline } \\
\text { Week } 52\end{array}$ & $\begin{array}{l}18.58 \\
22.20\end{array}$ & $\begin{array}{c}- \\
3.06\end{array}$ & $\begin{array}{c}- \\
\mathrm{C} \$ 81.74\end{array}$ \\
\hline
\end{tabular}

${ }^{\text {a }}$ Costs are presented in 2017 Canadian dollars.

the change in WLQ productivity loss score from baseline to week 52 was statistically significant $(p<0.001$ for total cohort, first treatment, and switched subgroups). ${ }^{23}$

\section{Weekly economic impact of improved productivity}

In the base case analysis, the total cohort gained $4.15 \mathrm{~h}$ of productive work, which translated into an average weekly gain of C $\$ 110.64$ at 52 weeks of treatment with vortioxetine compared to baseline (Table 4). Specifically, for the patients not being previously treated with another antidepressant for the current MDE (first treatment subgroup), an average weekly gain of C $\$ 140.32$ (5.26 h of work gained) was estimated, while a weekly gain of C\$81.74 (3.06 $\mathrm{h}$ of work gained) was estimated for patients who showed inadequate response to a previous antidepressant (switched subgroup) at 52 weeks compared to baseline.

\section{Cumulative economic impact of improved productivity at 52 weeks compared to baseline}

As presented in Figure 1, the cumulative economic impact of improved productivity showed potential savings of $\mathrm{C} \$ 5681$ per patient treated with vortioxetine throughout the 52 weeks. Based on the AtWoRC data collected at $4,8,12,26,39$, and 52 weeks, these gains would be even greater for patients newly treated with an antidepressant (C\$6459) compared to patients having inadequate response to a previous antidepressant (C\$4910). By considering an annual treatment cost of $20 \mathrm{mg}$ vortioxetine daily, the cumulative 52 -week cost of treatment was estimated at about $\mathrm{C} \$ 1130$. This represented a potential of a net saving ranging from $\mathrm{C} \$ 3780$ to $\mathrm{C} \$ 5329$ (C\$4550 for the total cohort) for productivity improvement following treatment with vortioxetine, when factoring in the cost of therapy.

\section{Complementary analysis using the mBOCF approach}

Similar results were obtained with the BOCF and the mBOCF approaches. When using the mBOCF approach, the average hours of absenteeism following 12 weeks of treatment reduced to $4.79(\mathrm{SD}=10.48), 3.60(\mathrm{SD}=$ $8.28)$, and 5.95 ( $\mathrm{SD}=12.16)$ missed hours for the total cohort, "first treatment", and "switched" subgroups, respectively. After 52 weeks of treatment with vortioxetine, workplace productivity improved to $7.89 \%$ (SD = $3.81), 7.81 \%(\mathrm{SD}=4.36)$, and $8.01 \%(\mathrm{SD}=3.18)$, representing 2.01, 2.08, and 1.94 missed hours for the total cohort, "first treatment", and "switched" subgroups, respectively (Table 5). The mBOCF results translated into comparable economic impact associated with improved work productivity in the base case approach.

\section{Discussion}

This analysis was designed to assess the economic impact of improved workplace productivity in patients with MDD who were being treated with vortioxetine, based on the results of the AtWoRC study. The AtWoRC study demonstrated that patients who were treated with vortioxetine experienced a significant improvement in workplace productivity associated with both absenteeism and presenteeism as soon as within 12 weeks of treatment. Here, it was found that this improved workplace productivity, which occurred concomitantly with clinical improvement in the mood, cognitive, and functional domains of MDD as shown previously, translated into a considerable economic impact for the employer and resulted in savings of $\mathrm{C} \$ 110.64$ weekly for up to 52 weeks of treatment with vortioxetine. ${ }^{22}$ In addition, the cumulative 52-week economic impact of improved productivity, compared to baseline, showed a potential of net saving of $\mathrm{C} \$ 5681$ when patients were treated with 
TABLE 5. Productivity data following 52 weeks of treatment with vortioxetine, according to the mBOCF approach

\begin{tabular}{|c|c|c|c|c|}
\hline \multirow[b]{2}{*}{ Cohort } & \multirow[b]{2}{*}{ Timescale } & \multirow{2}{*}{$\begin{array}{c}\text { Absenteeism } \\
\begin{array}{c}\text { Mean hours missed } \\
\text { from work }(S D)^{a}\end{array}\end{array}$} & \multicolumn{2}{|c|}{ Presenteeism } \\
\hline & & & $\begin{array}{l}\text { WLQ productivity } \\
\text { loss }(\%)(S D)^{\mathrm{a}}\end{array}$ & $\begin{array}{l}\text { Hours of reduced } \\
\text { productivity at work }\end{array}$ \\
\hline \multirow[t]{2}{*}{ Total } & Baseline & $8.1(12.09)$ & $13.4(4.55)$ & 2.96 \\
\hline & Week 52 & $4.8(10.48)$ & $7.9(3.81)$ & 2.01 \\
\hline \multirow[t]{2}{*}{ First treatment } & Baseline & $7.4(12.07)$ & $13.2(4.63)$ & 3.01 \\
\hline & Week 52 & $3.6(8.28)$ & $7.8(4.36)$ & 2.08 \\
\hline \multirow[t]{2}{*}{ Switch } & Baseline & $8.7(12.14)$ & $13.6(4.49)$ & 2.92 \\
\hline & Week 52 & $6.0(12.16)$ & $8.0(3.18)$ & 1.94 \\
\hline
\end{tabular}

${ }^{a}$ At week 52, values of the visit preceding the missing data for the first subsequent visit and baseline values for all other subsequent visits were attributed to all patients with missing data (total: $n=81$; first treatment: $n=35$; switch: $n=46$ for missed hours; and total: $n=76$, first treatment: $n=33$; switch: $n=43$ for WLQ) for the remaining weeks of the study period. The formula was used:

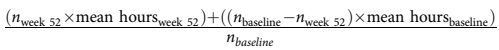

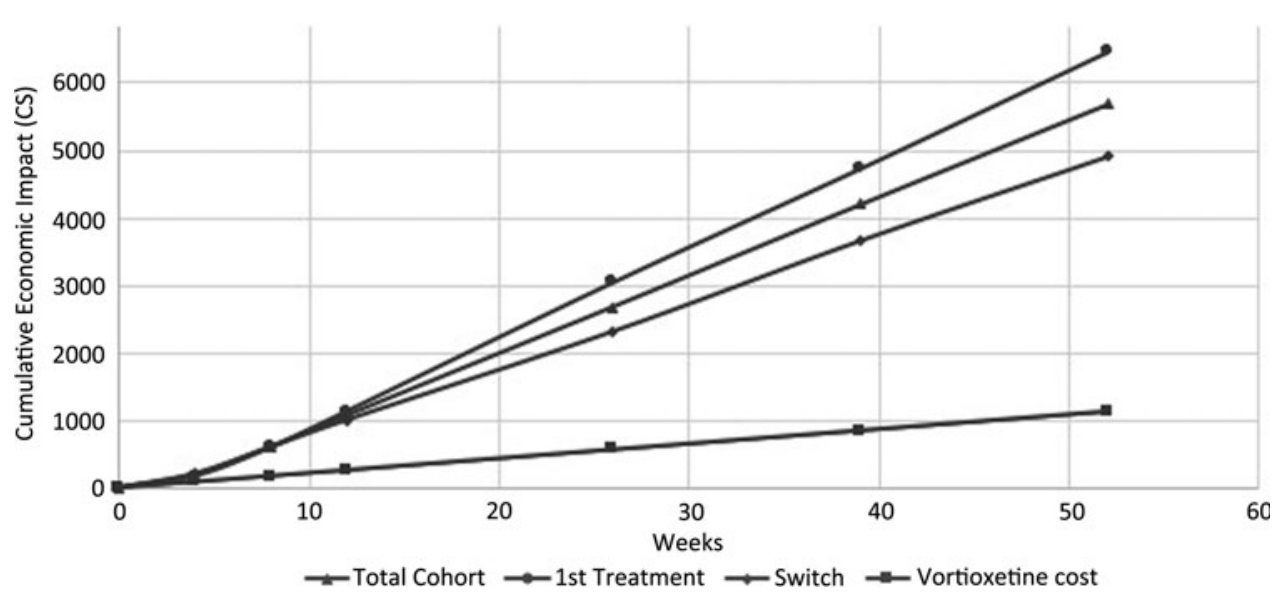

FIGURE 1. Cumulative economic impact of work productivity improvement after 52 weeks of treatment with vortioxetine, according to the BOCF approach.

vortioxetine, and $\mathrm{C} \$ 4550$ when factoring in the cost of therapy.

To our knowledge, no previous study had monetized the economic impact associated with improved productivity due to treatment with an antidepressant for patients with MDD in Canada. However, in 2006 Kessler et al. estimated an annual cost per patient of US $\$ 4426$ by way of productivity loss due to absenteeism and presenteeism for the overall population of patients suffering from MDD in the United States. ${ }^{32}$ More recently, in Spain, Romera et al. estimated the indirect cost of a depressive episode at $€ 3331$ per patient over 6 months for partial remission compared with $€ 1066$ per patient for complete remission. ${ }^{33}$ These two studies also used the HCM method to measure the economic impact of productivity loss in MDD. ${ }^{32,33}$

BOCF is a conservative approach for use in base case analysis. Indeed, we assumed that the loss to follow-up of patients would not benefit from improved work productivity from the time of dropout to the end of the study.
The mBOCF approach is less conservative, but probably more realistic than the BOCF analysis, since it recognized in the present study that patients lost to followup benefited from improved productivity associated with vortioxetine treatment at some point in the study, and that this effect lasted for some time before returning to its baseline value. This approach led to similar savings, supporting the robustness of the results.

In addition, the tools used to assess workplace productivity in the AtWoRC study have demonstrated high validity in mood disorders, such as MDD. Indeed, the WLQ questionnaire was explicitly validated for use in depression, since it was developed with a focus on patients with depression. Moreover, the use of the WPAI questionnaire in mood disorders was supported by active testing among patients with mood disorders, confirming a good level of comprehension within this population (cognitive debriefing). Those two questionnaires are based on a recall period of 7 days, thus limiting recall bias. $^{25,26}$ 
Despite the fact that two conservative methods of imputing missing data were used to ensure the validity of the results, this analysis has some limitations. Firstly, the HCM used for monetization of productivity loss has some limits when applied to long-term absence, since it assumes full employment and does not consider that absentee workers would be eventually replaced. ${ }^{34}$ However, considering that the analysis covered 52 weeks and was based on real-world data collected over the same period, the impact of this limitation would be minimal in this context. Secondly, almost half of the patients did not complete the 52-week study, with about $\mathbf{8 \%}$ of those patients having discontinued due to a lack of drug effect or inadequate response. ${ }^{22}$ To minimize the effect of patient attrition, a conservative approach was adopted using the BOCF approach to generate results that are reflective of a real-life clinical practice. Thirdly, a control group or a comparative treatment was also lacking. Thus, the results observed in the AtWoRC study may not be completely attributed to the drug effect, but the study was not designed to draw conclusions about the effectiveness of vortioxetine. Also, the mean hourly wage for a Canadian worker was used, which could be different than the hourly wage of persons with an MDD diagnosis. Moreover, the cumulative economic impact was based on the cost of vortioxetine in Canada, which could vary for other countries.

\section{Conclusion}

The results of the AtWoRC study revealed that patients with MDD who were treated with vortioxetine showed improvements in cognitive function and workplace productivity concomitantly with improved clinical outcomes. $^{22}$ The present study estimated the economic impact of this improvement in work productivity for patients treated with vortioxetine. This study suggests that improved productivity would result in substantial annual cost savings for employers and private payers. This study highlights the significant impairment in workplace productivity, which is an important topic for patients with MDD. Future studies should investigate the economic impact of other antidepressants and whether similar costs saving may be observed in other countries.

\section{Disclosures}

PeriPharm Inc. has received research funds from Lundbeck Canada Inc. to conduct this analysis. Jean Lachaine and Catherine Beauchemin are owners of PeriPharm, while Joëlle Bibeau and Julie Patenaude are employees of PeriPharm. Pratap Chokka has received honoraria for serving on advisory boards with Bristol Myers Squibb, Lundbeck, Janssen, Pfizer, Purdue, and Shire. He also had speaking engagements with Bristoll Myers Squibb, Lundbeck, Janssen, Pfizer, Shire, and
Purdue. He received research grants from Lundbeck, Janssen, and Pfizer. Joanna Bougie and Jean Proulx are employees of Lundbeck Canada.

\section{Funding}

Financial support for this analysis was provided by Lundbeck Canada Inc., which participated in the review and approval of this publication.

\section{REFERENCES:}

1. Collins JJ, Baase CM, Sharda CE, et al. The assessment of chronic health conditions on work performance, absence, and total economic impact for employers. J Occup Environ Med. 2005; 47(6): 547-557.

2. Greenberg PE, Fournier A-A, Sisitsky T, et al. The economic burden of adults with major depressive disorder in the United States (2005 and 2010). J Clin Psychiatry. 2015; 76(2): 155-162.

3. Greenberg PE, Kessler RC, Birnbaum HG, et al. The economic burden of depression in the United States: How did it change between 1990 and 2000? J Clin Psychiatry. 2003; 64(12): 1465-1475.

4. Lam RW, McIntosh D, Wang J, et al. Canadian Network for Mood and Anxiety Treatments (CANMAT) 2016 clinical guidelines for the management of adults with major depressive disorder: Section 1. Disease burden and principles of care. Can J Psychiatry. 2016; 61(9): 510-523.

5. Patten SB, Williams JV, Lavorato DH, et al. Descriptive epidemiology of major depressive disorder in Canada in 2012. Can J Psychiatry. 2015; 60(1): 23-30.

6. Lim K-L, Jacobs P, Ohinmaa A, et al. A new population-based measure of the economic burden of mental illness in Canada. Chronic Dis Can. 2008; 28(3): 92-98.

7. Stonebridge C, Sutherland G. Healthy Brains at Work: Estimating the Impact of Workplace Mental Health Benefits and Programs. The Conference Board of Canada, 1, 2016.

8. National Institute of Mental Health. Depression. October 2016 https://www.nimh.nih.gov/health/topics/depression/index.shtml, Access: 2017.

9. Lam RW, Kennedy SH, McIntyre RS, et al. Cognitive dysfunction in major depressive disorder: Effects on psychosocial functioning and implications for treatment. Can J Psychiatry. 2014; 59(12): 649-654.

10. Conradi HJ, Ormel J, de Jonge P. Presence of individual (residual) symptoms during depressive episodes and periods of remission: A 3-year prospective study. Psychol Med. 2011; 41(6): 1165-1174.

11. Fava M, Graves LM, Benazzi F, et al. A cross-sectional study of the prevalence of cognitive and physical symptoms during long-term antidepressant treatment. J Clin Psychiatry. 2006; 67(11): 1754.

12. American Psychiatric Association. Diagnostic and Statistical Manual of Mental Disorders (DSM-5ß). American Psychiatric Pub, United States; 2013.

13. Thase ME, Mahableshwarkar AR, Dragheim M, et al. A meta-analysis of randomized, placebo-controlled trials of vortioxetine for the treatment of major depressive disorder in adults. Eur Neuropsychopharmacol : J Eur Coll Neuropsychopharmacol. 2016; 26(6): 979-993.

14. Cipriani A, Furukawa TA, Salanti G, et al. Comparative efficacy and acceptability of 21 antidepressant drugs for the acute treatment of adults with major depressive disorder: a systematic review and network meta-analysis. Lancet (London, England). 2018; 391(10128): 1357-1366.

15. Alvarez E, Perez V, Dragheim M, et al. A double-blind, randomized, placebo-controlled, active reference study of Lu AA21004 in patients 
with major depressive disorder. Int J Neuropsychopharmacol. 2012; 15(5): 589-600

16. Baldwin DS, Loft H, Dragheim M. A randomised, double-blind, placebo controlled, duloxetine-referenced, fixed-dose study of three dosages of Lu AA21004 in acute treatment of major depressive disorder (MDD). Eur Neuropsychopharmacol. 2012; 22(7): 482-491.

17. Boulenger J-P, Loft H, Florea I. A randomized clinical study of Lu AA21004 in the prevention of relapse in patients with major depressive disorder. J Psychopharmacol. 2012; 26(11): 1408-1416.

18. Jain R, Mahableshwarkar AR, Jacobsen PL, et al. A randomized, double-blind, placebo-controlled 6-wk trial of the efficacy and tolerability of $5 \mathrm{mg}$ vortioxetine in adults with major depressive disorder. Int J Neuropsychopharmacol. 2012; 16(2): 313-321.

19. Katona C, Hansen T, Olsen CK. A randomized, double-blind, placebo-controlled, duloxetine-referenced, fixed-dose study comparing the efficacy and safety of Lu AA21004 in elderly patients with major depressive disorder. Int Clin Psychopharmacol. 2012; 27(4): 215-223.

20. Mahableshwarkar AR, Jacobsen PL, Chen Y. A randomized, doubleblind trial of $2.5 \mathrm{mg}$ and $5 \mathrm{mg}$ vortioxetine (Lu AA21004) versus placebo for 8 weeks in adults with major depressive disorder. Curr Med Res Opin. 2013; 29(3): 217-226.

21. Kennedy SH, Lam RW, McIntyre RS, et al. Canadian Network for Mood and Anxiety Treatments (CANMAT) 2016 clinical guidelines for the management of adults with major depressive disorder: Section 3. Pharmacological treatments. Can J Psychiatry. 2016; 61(9): $540-560$

22. Chokka P, Bougie J, Rampakakis E, et al. Assessment in Work Productivity and the Relationship with Cognitive Symptoms (AtWoRC): primary analysis from a Canadian open-label study of vortioxetine in patients with major depressive disorder (MDD). CNS Spectr. 2018; 1-10. doi:10.1017/s1092852918000913

23. Chokka P, Bougie J, Proulx J, et al. Long-term functioning outcomes are predicted by cognitive symptoms in working patients with major depressive disorder treated with vortioxetine: results from the AtWoRC study. CNS Spectr. 2019; 1-12. doi:10.1017/ S1092852919000786
24. Reilly Associates health outcomes research. http://www.reilly associates.net. Accessed January 11, 2018.

25. Despiegel N, Danchenko N, Francois C, et al. The use and performance of productivity scales to evaluate presenteeism in mood disorders. Value Health. 2012; 15(8): 1148-1161.

26. Lerner D, Amick III BC, Rogers WH, et al. The work limitations questionnaire. Med Care. 2001; 39(1): 72-85.

27. Statistics Canada. Average weekly hours (including overtime) for employees paid by the hour, by province and territory. 2017 ; http://www.statcan.gc.ca/tables-tableaux/sum-som/101/cst01/ labr82-eng.htm accessed date: December 2017.

28. Lofland JH, Pizzi L, Frick KD. A review of health-related workplace productivity loss instruments. Pharmacoeconomics. 2004; 22(3): 165-184.

29. Statistics Canada. Table 282-0073 7: Labour Force Survey estimates (LFS), wages of employees by job permanency, union coverage, sex and age group, unadjusted for seasonality. http://www5.statcan.gc. $\mathrm{ca} /$ cansim/a26?lang=eng\&retrLang=eng\&id $=2820073 \&$ tabMode $=$ dataTable $\& \mathrm{p} 1=1 \& \mathrm{p} 2=-1 \&$ srchLan=-1\&pattern=wage.

30. Lundbeck Canada Inc. Vortioxetine-Product monograph. Updated July 8th 2016. 2016.

31. Vieta E, Loft H, Florea I. Effectiveness of long-term vortioxetine treatment of patients with major depressive disorder. Eur Neuropsychopharmacol. 2017; 27(9): 877-884. doi:10.1016/ j.euroneuro.2017.06.012

32. Kessler RC, Akiskal HS, Ames M, et al. Prevalence and effects of mood disorders on work performance in a nationally representative sample of US workers. Am J Psychiatry. 2006; 163(9): 1561-1568.

33. Romera I, Perez V, Menchón J, et al. Social and occupational functioning impairment in patients in partial versus complete remission of a major depressive disorder episode. A six-month prospective epidemiological study. Eur Psychiatry. 2010; 25(1): 58-65.

34. Van den Hout W. The value of productivity: Human-capital versus friction-cost method. Ann Rheum Dis. 2010; 69(Suppl 1): i89-i91. 